\title{
Proliferative Peritoneal and pleURAl CESTOdiasis IN A CAT CAUSED BY METACESTODES OF MESOCESTOIDES SP. ANATOMOHISTOPATHOLOGICAL FINDINGS AND GENETIC IDENTIFICATION
}

\author{
ELENI C.*, SCARAMOZZINO P.*, BUSI M.**, INGROSSO S.**, D’AMELIO S.** \& DE LIBERATO C.*
}

\section{Summary:}

A 10-year-old female cat was brought to Istituto Zooprofilattico Sperimentale delle Regioni Lazio e Toscana for post-mortem examination. The animal used to live, together with 26 other cats, in the big terrace of an apartment at the $8^{\text {th }}$ floor in Rome, and was always fed with industrial pet food. Anamnesis referred balance troubles, vomit and convulsions, during a couple of days, followed by sudden death. At necropsy, the cat presented mucoid rhinitis, purulent tracheitis, small areas of pneumonia, dark spots in the liver, catarrhal-hemorrhagic gastritis, fibrinous enteritis and meningeal hyperemia. Thoracic and abdominal cavities were completely invaded by hundreds of larval stages of cestodes. The same parasites were also included in nodules in pancreatic, lung and kidney parenchyma. Microscopic examination of parasites allowed their identification as larval stages (metacestodes) of cestodes of the genus Mesocestoides. The molecular genotyping of the metacestodes indicates a close relationship with members of the genus Mesocestoides, although a significant variation was found with respect to the available sequences of other species of the genus.

KEY WORDS : Mesocestoides, metacestodes, cat, proliferative cestodiasis, parasitic ascite.
Résumé : Cestodose proloférANTE PleuRALE et péritonéale CHEZ un CHAT, CAUSÉE PAR DES MÉTACESTOdes (MESOCESTOIDES SP.). OBSERVATIONS ANATOMOHISTOPATHOLOGIQUES ET IDENTIFICATION GÉNÉTIQUE

Une chatte de 10 ans a été apportée à l'Istituto Zooprofilattico Sperimentale delle Regioni Lazio e Toscana pour un examen postmortem. L'animal examiné vivait au milieu d'une colonie de 26 chats, sur la terrasse d'un appartement à Rome, au huitième étage, et était nourri avec des aliments en boîte pour chat. L'anamnèse a mis en évidence des troubles de l'équilibre, des vomissements et convulsions, ceci pendant deux jours, le tout suivi d'une mort subite. À la nécropsie, la chatte présentait les signes suivants : rhinite mucoïde, trachéite sanieuse, zones pneumoniques circonscrites, taches foncées au niveau du foie, gastrite catarrhale hémorragique, entérite fibreuse et hyperhémie méningée. Les cavités thoraciques et abdominales étaient entièrement envahies par des centaines de cestodes au stade larvaire. On a pu constater la présence des mêmes parasites dans des nodules des parenchymes pancréatique, pulmonaire et rénal. L'analyse au microscope a permis d'identifier des stades larvaires (métacestodes) de cestodes du genre Mesocestoides. L'analyse moléculaire des métacestodes indique un rapport étroit avec des membres du genre Mesocestoides, bien qu'une variation significative ait été trouvée en ce qui concerne les données disponibles d'autres espèces du genre.

MOTS CLÉS : Mesocestoides, métacestode, chat, cestodose proliférante, ascite parasitaire.

gous insects (Soldatova, 1944; Quintavalla et al., 1996; Caruso et al., 2003). When an infected arthropod is eaten by a second intermediate host, second larval stage (metacestode, as tetrathyridium or acephalic form) is formed, and can be found in the serous cavities, especially peritoneal one, liver and lungs (Toplu et al., 2004) of amphibians, reptiles (lizards, snakes), birds and micro-mammals belonging to at least twohundred species (Chertkova \& Kosupko, 1978). Mammals usually involved in cycle as final hosts, can in some cases act as intermediate ones, harbouring tetrathyridia, by ingestion of a first larval stage within an arthropod or of a tetrathyridium within a second intermediate host. In this cases the metacestode penetrates the intestinal wall, invades the peritoneal cavity and a systemic infestation occurs, expanding to many organs and tissues. Tetrathyridia have the unique ability among metazoan parasites to undergo asexual reproduction by budding or binary fission and adapt to low-oxygen 
environments within body cavities and organs (Caruso et al., 2003), leading to marked parasitic infection even starting from a single specimen. This kind of infections, rather uncommon but probably under-diagnosed, can cause severe clinical features (ascites, abdominal distension, peritonitis) and occasionally death in dogs and other animals (Guillot \& Green, 1992; Fincham et al., 1995; Bonfanti et al., 2004). Sometimes, instead of the normal tetrathyridium, an acephalic form, without the typical four suckers, can be found (Crosbie et al., 1998; Caruso et al., 2003).

While infections by adult Mesocestoides sp. in cats are quite common in Europe, feline metacestodiasis is a rather uncommon finding, and it is usually casually reported at necropsy or during surgical operations (Paoluzzi, 1947; Canestri Trotti \& Tumino, 1991; Quintavalla et al., 1996; Venco et al., 2005). We hereby report a case of peritoneal infection by Mesocestoides sp. occurred in a cat belonging to a colony in Rome, Italy, and diagnosed at necropsy. This case was considered interesting because of the unusualness of the finding in cats, some interesting anatomohistopathological features and some parasitological and molecular considerations regarding parasite taxonomy and way of infection.

\section{CASE REPORT}

I n march 2005, a female cat, 10-years-old, was brought by its owner to the Istituto Zooprofilattico Sperimentale delle Regioni Lazio e Toscana (IZSLT) in Rome, for post-mortem examination. The anamnesis referred balance troubles, vomit and convulsions, during a couple of days, occurred after a change of feeding from a commercial pet food to an other of the same type (poultry and beef), but produced by a different firm. The cat used to live in an apartment in Rome, together with 26 other cats, all of them having access to a big terrace at the $8^{\text {th }}$ floor. Cats were only fed by industrial food. The owner was sure in imputing the sickness to the new pet food, which was imported from an eastern country. The suspected food poisoning interested almost all the cats of the colony, one of which died few hours after the first one, presenting the same symptoms.

\section{ANATOMO-PATHOLOGY}

At the necropsy, the cat presented the following lesions: mucoid rhinitis, purulent tracheitis, small areas of pneumonia, dark spots in the liver, catarrhal-hemorrhagic gastritis and fibrinous enteritis. Meningeal hyperemia was also noticed. Thoracic and abdominal cavities were completely invaded by hundreds of white, flattened, $0.5-3 \mathrm{~cm}$ long, immature tapeworms identified later as larval stages of cestodes. Most of them were free in the cavities, whereas others were connected with serosae or partially or totally included in granulomatous masses in pancreatic, lung and kidney parenchyma.

\section{HisTO-PATHOLOGY}

For histopathologic examinations, samples of lung, pancreas, kidney, liver, hearth, intestine and spleen were fixed in buffered $10 \%$ formalin, sectioned at $6 \mu \mathrm{m}$ and stained with hematoxylin and eosin.

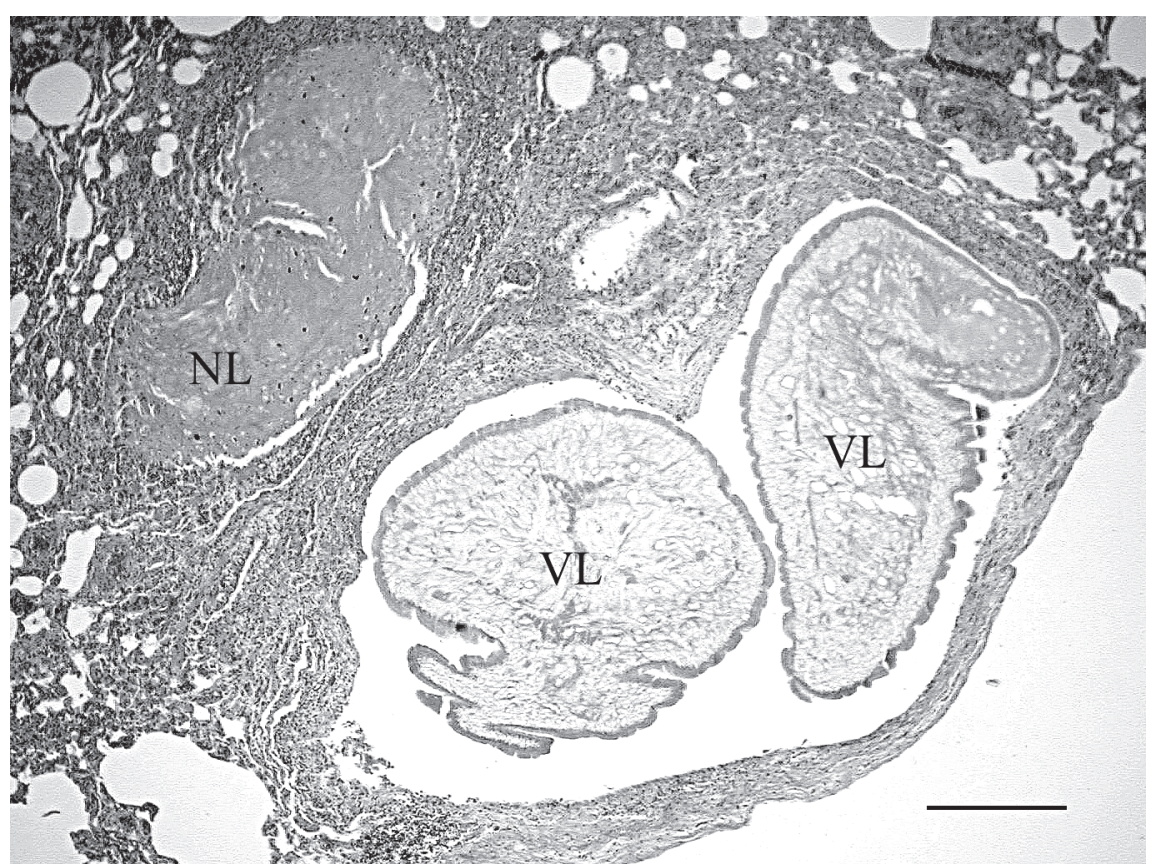

Fig. 1. - Lung: Granuloma containing viable (VL) and necrotic (NL) larval forms. Hematoxilyn and eosin (HE). $40 \times$ (Bar scale $300 \mu \mathrm{m})$. 
Microscopically, in lungs, pancreas and kidneys, granulomas were characterized by cystic formations surrounded by a loose fibrous capsule infiltrated by lymphocytes, plasma cells and a few eosinophils (Fig. 1). These cysts, corresponding to metacestodes, had convoluted borders with a thick eosinophilic tegument; the stroma of the parasitic body included a loose mesenchymal network with parenchymal and muscle cells, some calcareous corpuscles and excretory canals. Some specimens showed a medial bilateral invagination, probably representing the beginning of a binary fission process (Buergelt et al., 1984). Pancreas lesions included severe cells degeneration, fibrosis and scattered lymphocytic inflammation. Lungs presented purulent bronchiolitis and diffuse hyperemia. Kidneys showed areas of interstitial nephritis, tubular cells degeneration and fibrosis. Liver presented severe steatosis and diffuse hyperemia. Others processed organs didn't show any pathological lesion.

Because of the unusualness of the case, the owner was asked to bring the second dead animal, which was not parasitized and presented generic post mortem signs as lung emphysema, kidney hyperemia and serious liver degeneration with a necrotic nodule $1 \mathrm{~cm}$ large. At histo-pathology the most important lesion was severe and diffuse hepatic steatosis, associated with some areas of purulent hepatitis; the necrotic nodule corresponded to a biliary cystadenoma. No parasites were seen in organs. Bacteriological examination of cats organs revealed a mixed infection by Escherichia coli and Serratia sp. in lung and brain in the first one and by E. coli in spleen and thoracic fluid in the second one. Both animals were regularly examined for Salmonella following standard procedures in the bacteriological lab of the IZSLT, and resulted negative.

Because of the suspicion of food poisoning, 12 cans of several batches of the food product used to feed cats were analysed for sterility and $\mathrm{pH}$, and were regular. Suspecting a food-borne origin for parasitic infection, the same cans were inspected for parasites with negative result.

\section{PARASITE IDENTIFICATION}

\section{MORPHOLOGY}

P arasites were $0.5-3 \mathrm{~cm}$ long, flattened, whitish in colour, claviform. Anterior extremity was enlarged, globous, with a deep apical invagination and many transverse superficial folds, more numerous near the anterior extremity, but present along the whole body. Posterior extremity was gradually tapering and pointed at the tip or slightly invaginated. According to these features, larval forms found at necropsy were identified as acephalic metacestodes belonging to the order Cyclophyllidea.

Due to the aspecificity of larval morphology, a molecular analysis was performed.

\section{Molecular BiOLOGY}

DNA was extracted from ten tapeworms using the Wizard ${ }^{\circledR}$ Genomic DNA purification kit (Promega), following the manufacturers' instructions. A fragment of about 366-bp of the mitochondrial cytochrome $c$ oxidase subunit 1 (CO1) gene was amplified using primers described by Bowles et al. (1992) formerly designed for Fasciola hepatica. Primers had following nucleotide composition:

Forward JB3. 5'-TTT TTT GGG CAT CCT GAG GTT TAT-3

Reverse JB4,5. 5'-TAA AGA AAG AAC ATA ATG AAA ATG-3

The PCR reactions were performed in a total volume of $50 \mu \mathrm{l}$ under the following cycling conditions: initial denaturation step $94^{\circ} \mathrm{C}$ for $10 \mathrm{~min}$, followed by 35 cycles, $94^{\circ} \mathrm{C}$ for $30 \mathrm{sec}, 50^{\circ} \mathrm{C}$ for $45 \mathrm{sec}$, and $72^{\circ} \mathrm{C}$ for $40 \mathrm{sec}$, finally $7 \mathrm{~min}$ at $72^{\circ} \mathrm{C}$.

In addition, from three individuals, a fragment of about 311-bp of the mitochondrial 12S rDNA was amplified using a pair of cestode-specific primers constructed by von Nickisch-Rosenegk et al. (1999). The sequences of each primers were:

Forward P60. 5'-TTA AGA TAT ATG TGG TAC AGG ATT AGA TAC CC-3'

Reverse P375. 5'-AAC CGA GGG TGA CGG GCG GTG TGT ACC-3'

The PCR reaction was performed in a total volume of $50 \mu \mathrm{l}$ under the following cycling conditions: initial denaturation step $94^{\circ} \mathrm{C}$ for $10 \mathrm{~min}$, followed by 30 cycles, $94^{\circ} \mathrm{C}$ for $30 \mathrm{sec}, 55^{\circ} \mathrm{C}$ for $60 \mathrm{sec}$, and $72^{\circ} \mathrm{C}$ for $60 \mathrm{sec}$, finally $7 \mathrm{~min}$ at $72^{\circ} \mathrm{C}$.

PCR products were electrophoresed through $1 \%$ agarose gels and detected by ethidium bromide staining. The amplicons obtained were purified over spin columns (Nucleo Spin Extract-MN) and sequenced.

Partial DNA sequences of the cytochrome oxidase I of ten individual metacestodes collected in the host were obtained and aligned with the only available sequences of Mesocestoides for CO1, that is M. corti (Accession number AB033413).

All the individual sequences were identical and differed from the $M$. corti sequence at $11.99 \%$ nucleotide sites. Partial DNA sequences of the mitochondrial ribosomal short subunit (12S) of three individual metacestodes were aligned with the available sequences of Mesocestoides for 12S, that are M. corti, M. vogae, M. lineatus and M. leptothylacus (Accession numbers AB031363, L49448, L49450, L49451, respectively). It should be noticed that $M$. corti is now considered as a synonym of M. vogae (Etges, 1991). 


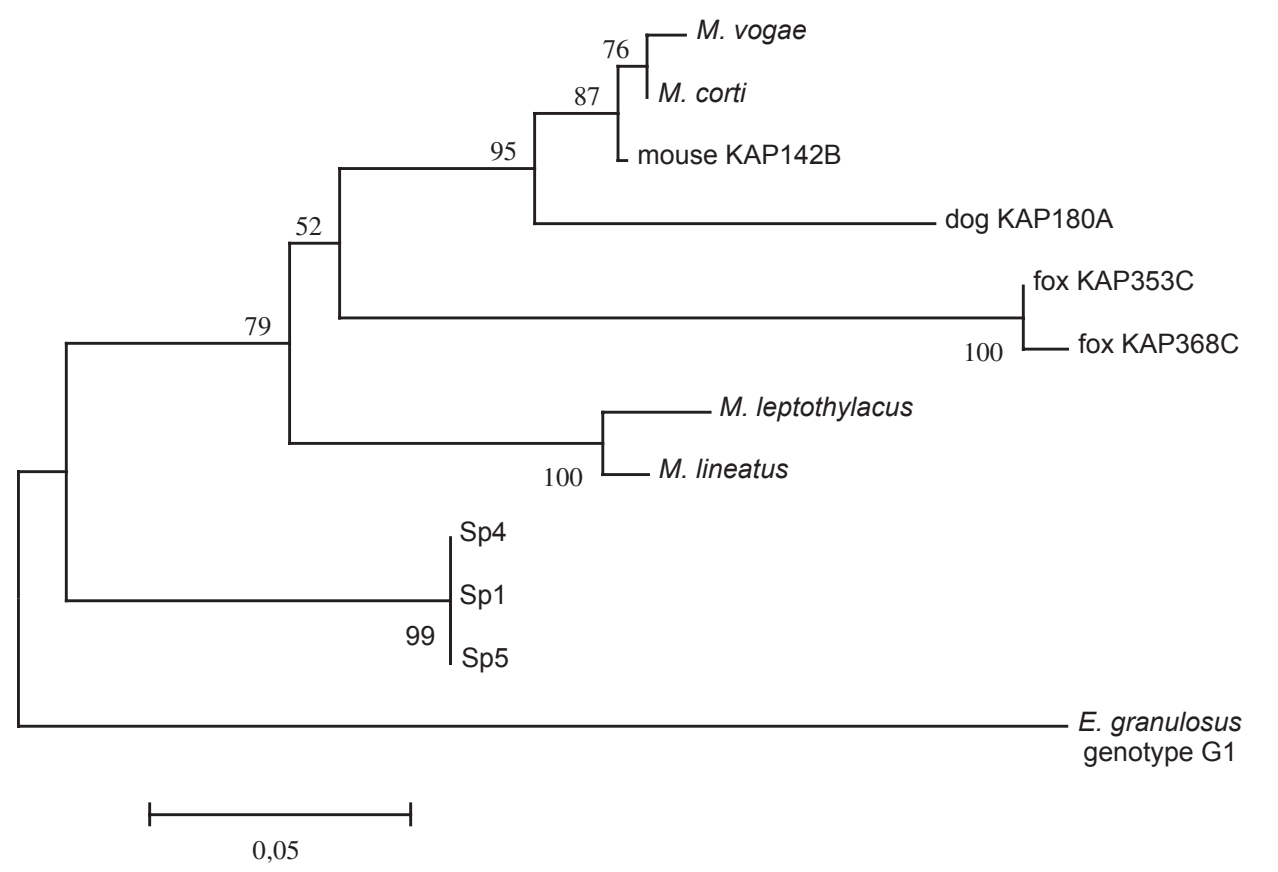

Fig. 2. - Neighbor-joining phenetic tree based on a Kimura 2parameter distance matrix, showing the relationships between three isolates collected in a massive infestation of a domestic cat in comparison with known sequences of Mesocestoides spp., using Echinococcus granulosus as outgroup. MouseKAP142B, dogKAP180A, foxKAP353C and foxKAP368C refer to GeneBank accession numbers DQ102756, DQ102750, DQ104225 and DQ104224, respectively. Numbers at nodes indicate bootstrap values after 1,000 replications.

All the individual sequences from the collected samples were identical and differences from the other Mesocestoides sequences ranged from $6.62 \%$ to $9.60 \%$. In CO1 gene, most of the variable sites were at the third codon position, thus representing silent mutations.

An extensive analysis of sequence variation within Mesocestoides infecting canids in western North America, was carried out by Crosbie et al. (2000) using nuclear ribosomal DNA (18S) sequence to identify amorphous, acephalic metacestodes.

More recently, a molecular characterization of Mesocestoides spp. isolates was carried out by Padgett et al. (2005), showing three distinct clades A, B and C, representing three putative Mesocestoides taxa, regarded as valid species, one (B) corresponding to M. vogae.

Comparison of three $12 \mathrm{~S}$ sequences (SP1, SP4 and SP5) with three isolates representative of Padgett's A, B and $\mathrm{C}$ clades demonstrates that cestodes from the present study are genetically different also from these specimens, with nucleotide differences ranging from $10.1 \%$ to $14.9 \%$. Moreover, the Neighbor-joining phenetic tree shown in figure 2 indicates that the SP1, SP 4 and SP5 clade is located, with strong bootstrap values, within the clade of Mesocestoides, thus supporting the sequencebased assignment to this genus, although the only outgroup available, a sequence of Echinococcus granulosus, is weakly related to Mesocestoides.

\section{DISCUSSION}

I arval forms of the genus Mesocestoides are known to cause proliferative infections in many hosts. While the presence of tetrathyridia or acephalic forms in dogs can provoke symptoms like anorexia, vomiting, weakness, lethargy, weight loss and abdominal effusion, they are commonly believed to be a-symptomatic in cats (Canestri Trotti \& Tumino, 1991; Quintavalla et al., 1996). The signs showed by our cat two days before death were not specific and probably connected to food poisoning and consequent severe lesions of liver and gastroenteric organs. The massive presence of parasitic larvae could have contributed to the death of the animal, since almost all the other cats recovered after a similar symptomatology. The larval localization here observed is concordant with previous observations by other authors in dogs and primates (Williams et al., 1985; Guillot \& Green, 1992; Fincham et al., 1995; Toplu et al., 2004). Parasites are described generally free in body cavities (peritoneal cavity in particular) and sometimes attached to the serosal surfaces; less frequently they are present inside the organs like chronic granulomatous masses (in dogs: Williams et al., 1985 and Toplu et al., 2004; in cats: Buergelt et al., 1984). Microscopically, tissue lesions showed the same characteristics as already described (Buergelt et al., 1984; Williams et al., 1985; Guillot \& Green, 1992; Fincham et al., 1995; Toplu et al., 2004).

At present, seven species of the genus Mesocestoides are recorded in Europe (Yanchev, 1986). Morphological evidences support genus identification, even if metacestodes are known to display a great variability in shape and measures (Literàk et al., 2004), thus making morphology not suitable for specific identification. Even differentiation from other cestode larval forms can be difficult, mainly when acephalic metacestodes are found. In some cases spargana of pseudophyllidean tapeworms (i.e. Spirometra sp.) can cause proliferative infestations 
in cats, sometimes with similar anatomohistopathological features and with the same lack of taxonomically relevant morphological characters (Buergelt et al., 1984). Hence the importance of a molecular identification.

The molecular genotyping of the metacestodes indicates a close relationship with members of the genus Mesocestoides, although a significant variation was found with respect to the available sequences of other species of the genus, M. corti (= M. vogae), M. lineatus and M. leptothylacus and with three recently recognized taxa within the genus. The three individual cestodes sequenced for the $12 \mathrm{~S}$ mitochondrial gene therefore form an uniform clade, distinct from all the other available sequences, well within the Mesocestoides spp. clade (Fig. 2). Padgett et al. (2005) advocate that the distinct phylogenetic lineages characterising clades A, $\mathrm{B}$ and $\mathrm{C}$ should be recognized as separate species, with clade $\mathrm{B}$ corresponding to the species M. vogae. Consequently isolates SP1, SP2 and SP5 could be members of a different species with respect to M. vogae, M. lineatus and M. leptothylacus and from the two undescribed species corresponding to Padgett's clades A and C. Although the sequences here obtained do not correspond to any of the $12 \mathrm{~S}$ or CO1 sequences available for Mesocestoides species, we assume that the similarities observed allow us to assign these samples to the genus Mesocestoides. However it is not possible to achieve a correct identification at species as well as to exclude they may represent a new, undescribed species.

Problems arise when considering the possible route of infection of a parasite with a three host cycle in a cat living at the $8^{\text {th }}$ floor in a big city and exclusively fed with industrial food. Moreover, Mesocestoides infections occur exclusively in scavenging or preying animals (Crosbie et al., 2000). For the hosts involved and the needed ambient fecalization, Mesocestoididae life cycle appears more probable to occur in rural rather than urban habitats. Coprophagous arthropods, rodents, birds and reptiles are ubiquitous and widespread in such habitats, and the attitude of cats to prey on birds, lizards, small snakes and mice makes it possible the acquiring of the parasite. A possible way of infection of our cat could be the common starling (Sturnus vulgaris), recently found to harbour Mesocestoides larvae in the Czech Republic (Literak et al., 2004). This species, present in Rome with enormous colonies, daily migrates from the night resting sites in the centre of the city to the surrounding feeding rural areas, thus possibly acting as a carrier of the parasite within the city.

\section{REFERENCES}

Bonfanti U., Bertazzolo W., Pagliaro L., Demarco B., Venco L., CASIRAghi L. \& BANDi C. Clinical, cytological and molecular evidence of Mesocestoides sp. infection in a dog from
Italy. Journal of Veterinary Medicine, Series A, 2004, 51, 435-438.

Bowles J., Blair D. \& McManus D.P. Genetic variants within the genus Echinococcus identified by mitochondrial DNA. Molecular Biochemical Parasitology, 1992, 54 (2), 165-173.

Buergelt C.D., Greiner E.C. \& Senior D.F. Proliferative sparganosis in a cat. Journal of Parasitology, 1984, 70 (1), 121125.

Canestri Trotti G. \& Tumino G. Peritonite parassitaria in carnivori domestici da stadi larvali di Mesocestoides sp.: tre casi in Sicilia. Atti della Società Italiana delle Scienze Veterinarie, 1991, 45, 1317-1320.

Caruso K.J., James M.P., Fisher D., Paulson R.L. \& ChristoPHER M.M. Cytologic diagnosis of peritoneal cestodiasis in dogs caused by Mesocestoides sp. Veterinary Clinical Pathology, 2003, 32 (2), 50-60.

Chertkova A.N. \& Kosupko G.A. The suborder Mesocestoidata Skryabin, 1940. In: Principles of Cestodology. Vol. 9. Tetrabothriata and Mesocestoidata - Cestodes of birds and mammals. Moskow: Nauka, 1978, 118-229.

Crosbie P.R., Boyce W.M., Platzer E.G., Nadler S.A. \& KerNER C. Diagnostic procedures and treatment of eleven dogs with peritoneal infections caused by Mesocestoides spp. Journal of the American Veterinary Medicine Association, 1998, 213, 1578-1583.

Crosbie P.R., Nadler S.A., Platzer E.G., Kerner C., Mariaux J. \& Boyce W.M. Molecular systematics of Mesocestoides spp (Cestoda: Mesocestoididae) from domestic dogs (Canis familiaris) and coyotes (Canis latrans). The Journal of Parasitology, 2000 86, 350-357.

Crosbie P.R., Padgett K.A. \& Boyce W.M. Mesocestoides sp. tapeworm infections in dogs in California. The Califormian veterinarian, 2000, 15-16, 27-28.

ETGES F.R. The proliferative tetrathyridium of Mesocestoides vogae sp. n. (Cestoda). Journal of the Helminthological Society of Washington, 1991, 58, 181-185.

Fincham J.E., Seier J.V., Verster A., Rose A.G., Taljaard J.J., WoODROOF C.W. \& RuTHERFOORD G.S. Pleural Mesocestoides and cardiac shock in an obese vervet monkey (Cercopithecus aethiops). Veterinary Pathology, 1995, 32 (3), 330333.

Fuentes M.V., Galàn-Puchades M.T. \& Malone J. A new case report of human Mesocestoides infection in the United States. American Journal of Tropical Medicine and Hygiene, 2003, 68 (5), 566-567.

Guillot L.M. \& Green L.C. Pulmonary cestodiasis in acynomolgus monkey (Macaca fascicularis). Laboratory Animal Sciences, 1992, 42, 158-160.

Keeseon S.E., Seung-Ho K. \& Hang-Jong R. Second case of human infection with Mesocestoides lineatus in Korea. Korean Journal of Parasitology, 1992, 30 (2), 147-150.

Literak I., Olson P.D., Georgiev B.B. \& Spakulova M. First record of metacestodes of Mesocestoides sp. in the common starling (Sturnus vulgaris) in Europe, with an 18S rDNA characterisation of the isolate. Folia Parasitologica, 2004, 51 (1), 45-49.

Padgett K.A., Nadler S.A., Munson L., Sacks B. \& Boyce W.M. Systematics of Mesocestoides (Cestoda: Mesocestoididae): 
evaluation of molecular and morphological variation among isolates. Journal of Parasitology, 2005, 91 (6), 1435-1443.

PAoluzzi L. Di un caso d'infestazione massiva da larve del Mesocestoides lineatus. La Nuova Veterinaria, 1947, 28, 340.

Quintavalla F., Pattacini O., Borciani I., Micagni G. \& NorCIO C. Su un caso di tetratiridiosi felina. Veterinaria, 1996, 2, 99-102.

Smith J.D. Eucestoda: Cyclophyllidea. In: Introduction to animal parasitology. $3^{\text {rd }}$ ed. Cambridge University Press. Cambridge, 1994, 342-344.

Soldatova A.P. A contribution to the study of the development cycle in the cestode Mesocestoides lineatus (Goetze, 1782), parasitic in carnivorous mammals. Compte Rendus de l'Académie des Sciences de l'URSS, 1944, 45, 310-312.

TOPlu N., Yildiz K. \& TunAY R. Massive cystic tetrathyridiosis in a dog. Journal of Small Animal Practice, 2004, 45, 410412.

Venco L., Kramer L., Pagliaro L. \& Genchi C. Ultrasonographic features of peritoneal cestodiasis by Mesocestoides sp. in a dog and in a cat. Veterinary Radiology Ultrasound, 2005, 46 (5), 417-422.

von Nickisch-Rosenegk M., Silva-Gonzalez R. \& Lucius R. Modification of universal $12 \mathrm{~S}$ rDNA primers for specific amplification of contaminated Taenia spp. (Cestoda) gDNA enabling phylogenetic studies. Parasitology Research, 1999, 85 (10), 819-825.

Williams J.F., Lindsay M. \& ENGELKIRK P. Peritoneal cestodiasis in a dog. Journal of the American Veterinary Medicine Association, 1985, 186 (10), 1103-1105.

YANCHEV Y. On the morphology, taxonomy and distribution of the species of the genus Mesocestoides Vailland, 1863 in Bulgaria. Khelmintologiya, 1986, 21, 45-65.

Reçu le 14 octobre 2006 Accepté le 19 décembre 2006 